\title{
Esporotricose cutânea disseminada como manifestação inicial da síndrome da imunodeficiência adquirida - relato de caso
}

\author{
Acquired immunodeficiency syndrome presenting as disseminated \\ cutaneous sporotrichosis - case report \\ Roberto da Justa P. Neto, Alcyone A. Machado, Gleusa de Costro, \\ Alda S. dos Sontos Punglio e Roberto Martinez
}

\begin{abstract}
Resumo Os autores relatam caso de infecção cutânea disseminada pelo Sporothrix schenckii em paciente de 30 anos, previamente assintomático e portador de infecção pelo HIV. Observou-se comprometimento cutâneo extenso com coleções supurativas e ulcerações. $O$ agente foi isolado em cultura de abscesso. O tratamento com anfotericina B forma lipossomal mostrou-se eficaz.
\end{abstract}

Palavras-chaves: Esporotricose. HIV. SIDA. Anfotericina B lipossomal.

\begin{abstract}
TThe authors report a case of disseminated cutaneous infection with Sporothrix schenckii in a previously asymptomatic HIV-infected 30 year-old man. Extensive cutaneous involvement was observed with suppurative collections and ulcerations. The agent was isolated in culture. Treatment with liposomal amphotericin B proved to be effective.
\end{abstract}

Key-words: Sporotrichosis. HIV. AIDS. Liposomal amphotericin B.

Sporothrix schenckii é um fungo dimórfico que vive no solo em associação com restos vegetais, em regiões de climas temperado e tropical úmidos. Esporotricose é a doença em geral resultante da inoculação direta de conídios do S. schenckii na derma. Após a inoculação, este agente pode causar infecção cutânea ou subcutânea que geralmente é localizada, podendo associar-se a comprometimento linfático regional. Formas disseminadas da doença são menos comuns e podem estar associadas a algum grau de imunodeficiência20 22. Na literatura encontramos alguns relatos de esporotricose em pacientes infectados pelo vírus da imunodeficiência humana (HIV), mas poucos casos foram relatados desta doença como manifestação inicial da síndrome da imunodeficiência adquirida (SIDA)2 61824 .

$O$ presente relato trata de um caso bem documentado de esporotricose cutânea disseminada como manifestação inicial da SIDA. Obteve-se boa resposta terapêutica com anfotericina B forma lipossomal.

\section{RELATO DO CASO}

Paciente masculino, 30 anos, negro, natural e residente na zona urbana de Ribeirão Preto, no nordeste do Estado de São Paulo, desenvolvendo atividade de servente de pedreiro, foi encaminhado ao Serviço de Moléstias Infecciosas do Hospital das Clínicas da Faculdade de Medicina de Ribeirão Preto em maio de 1997. Referia que há 2 meses começou a apresentar

Serviço de Moléstias Infecciosas e Tropicais do Departamento de Clínica Médica da Faculdade de Medicina de Ribeirão Preto da Universidade de São Paulo. Ribeirão Preto, São Paulo, Brasil.

Endereço para correspondência: Prof. Roberto Martinez. Depto. de Clínica Médica/FMRP/USP. Av. Bandeirantes 3900, Monte Alegre, 14048-900 Ribeirão Preto, SP, Brasil.

Fax: 5516 633-6695.

Recebido para publicação em 29/7/98. 
nódulos subcutâneos, indolores e nãopruriginosos, inicialmente em braço direito, progredindo com comprometimento de membro superior esquerdo, tronco, e membros inferiores. A maioria evoluiu em 1 mês com fistulização para pele, saída de secreção purulenta e posterior ulceração e dificuldade para cicatrização. Além das queixas dermatológicas, o paciente relatava ainda diminuição do apetite, adinamia e perda de peso. Não apresentava queixas respiratórias ou neurológicas, bem como não relatou febre durante o período. Era etilista crônico moderado e usuário de drogas endovenosas há 6 anos. Ao exame clínico, os nódulos mediam 2 a $3 \mathrm{~cm}$ de diâmetro, com consistência cística, indolores, normocrômicos (Figura 1). Observou-se formação de cordão de nódulos subcutâneos em trajeto de drenagem linfática de braço direito, caracterizando um rosário (Figura 2). Em algumas áreas (braço, tronco e coxas) havia fistulização para pele e formação de úlceras (Figura 3). Não havia lesões em mucosa oral.

Exames laboratoriais evidenciaram anemia leve $(\mathrm{Hb} 11,5 \mathrm{~g} / \mathrm{dl} ; \mathrm{Ht} \mathrm{33,1 \% )}$ e velocidade de hemosedimentação de $56 \mathrm{~mm}$ na primeira hora. Pesquisa de anticorpos específicos para HIV no soro resultou positiva pelos métodos imunoenzimático (ELISA-Abbott) e de aglutinação de partículas de gelatina (Serodia/Fujirebio). A contagem de linfócitos CD4+ por citometria de fluxo foi de 81,3 céls $/ \mathrm{mm}^{3}$. Exame radiológico de tórax foi normal. Ao estudo anatomopatológico da biópsia, observou-se derme com moderado infiltrado inflamatório por mono e polimorfonucleares; coloração específica para fungo (GMS) mostrou estruturas arredondadas com esporulação única. Culturas foram realizadas

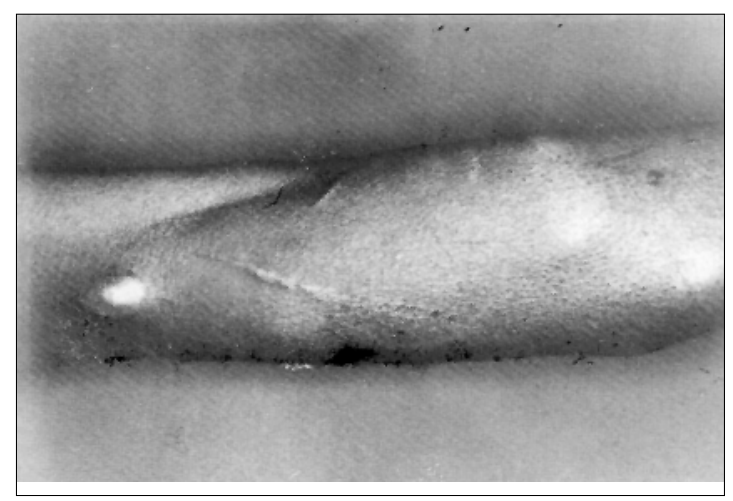

Figura 1 - Nódulos subcutâneos em membro superior esquerdo em decorrência de infecção por S. schenckii.

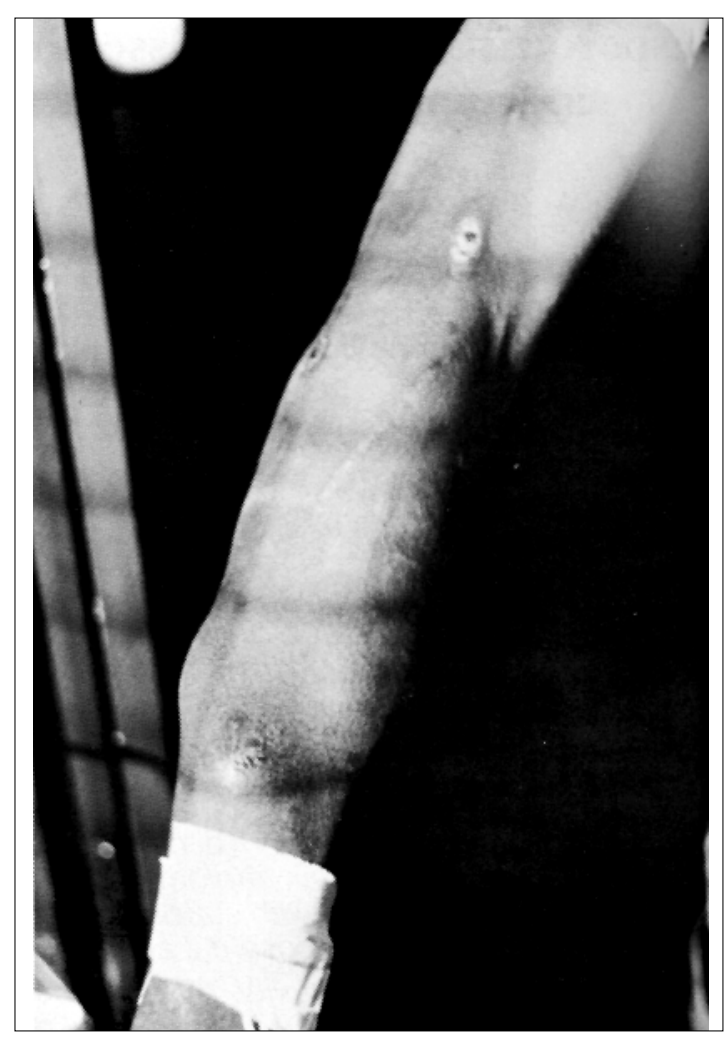

Figura 2 - Nódulos subcutâneos em trajeto de drenagem linfática de membro superior direito.

a partir de secreção purulenta aspirada de nódulo e de fragmento de biópsia de lesão cutânea. Houve crescimento de colônias típicas de $S$. schenckii a partir de ambas as amostras

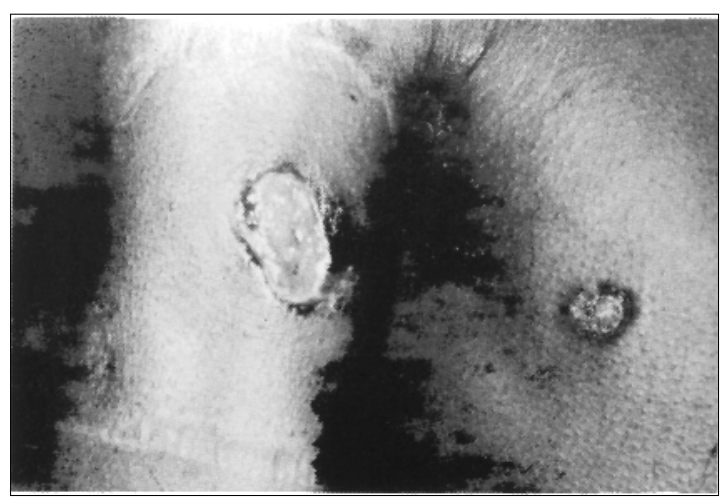

Figura 3 - Úlceras rasas e bem delimitadas em braço direito e região peitoral direita causadas por infecção por S. schenckii. 
inoculadas em meio Ágar-Sabouraud a $25^{\circ} \mathrm{C}$. Com o exoantígeno obtido de cultura líquida deste fungo realizou-se a pesquisa de anticorpos anti$S$. schenckii no soro do paciente, obtendo-se título de $1 / 32$ pelo método de contra-imunoeletroforese (Figura 4). Decidiu-se por realizar tratamento com anfotericina $B$ intravenosa $(0,7$ a $1 \mathrm{mg} / \mathrm{kg} / \mathrm{dia}$ ). Após $355 \mathrm{mg}$ de dose acumulada desenvolveu-se elevação importante dos níveis séricos de uréia e creatinina, sendo necessário interrupção provisória da medicação. Optou-se

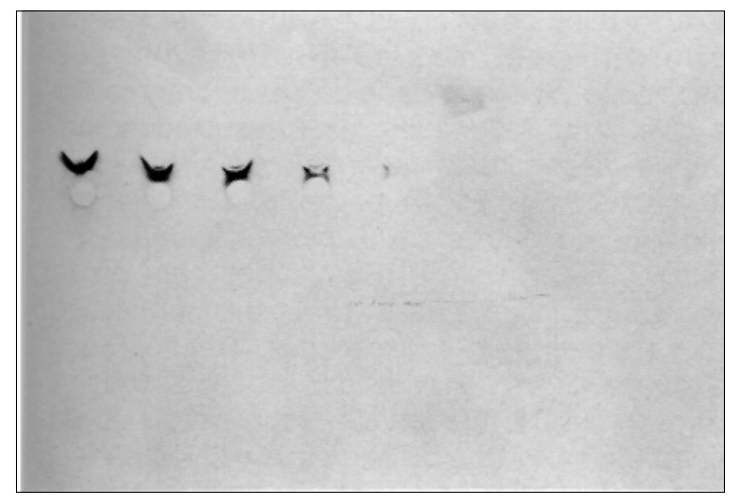

Figura 4 - Pesquisa de anticorpos anti-S. schenckii pelo método de contra-imunoeletroforese - placa mostrando linha de precipitação até diluição 1/32. por retomar o tratamento com anfotericina $\mathrm{B}$ forma lipossomal, havendo boa tolerância e completando dose total acumulada de 2045mg. Observou-se excelente resposta terapêutica com regressão completa das lesões (Figura 5) e da insuficiência renal, introduzindo-se $400 \mathrm{mg} / \mathrm{dia}$ de cetoconazol como tratamento de manutenção. $O$ paciente também vem usando os antiretrovirais $\mathrm{AZT}, \mathrm{DDI}$ e ritonavir e permanece assintomático após 12 meses de seguimento ambulatorial.

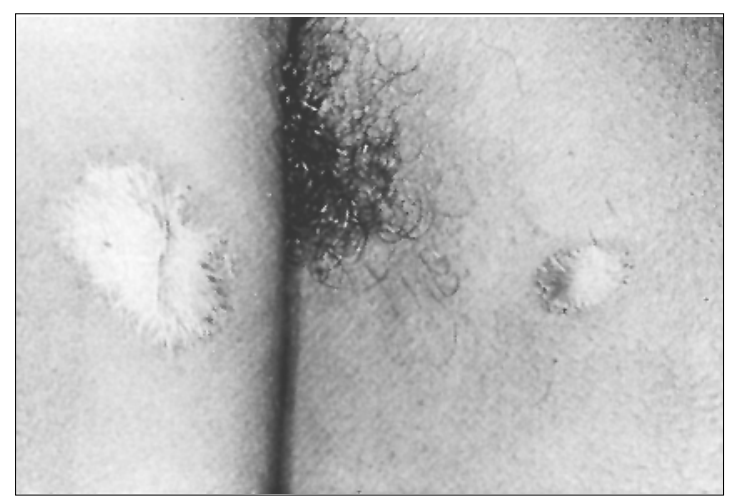

Figura 5 - Cicatrização completa de lesões após tratamento com anfotericina $B$ forma lipossomal.

\section{DISCUSSÃO}

A esporotricose é doença comum em áreas de clima predominantemente úmido e temperado. No Brasil, em algumas regiões do Sul, é a mais freqüente das micoses subcutâneas 5 12. É considerada doença ocupacional, ocorrendo com maior freqüência em trabalhadores que lidam com solos e vegetais contaminados com esporos do $S$. schenckii. Os grupos de maior risco são jardineiros, floristas, horticulturistas e agricultores. Entretanto, há relatos de epidemias menores entre pessoas que manusearam palha, feno e tijolos 5 . O paciente do caso apresentado desenvolvia atividade de servente de pedreiro e, provavelmente, contraiu a infecção pelo S. schenckii no exercício de sua profissão, com a inoculação inicial ocorrendo em membro superior direito onde surgiram as primeiras lesões.

A esporotricose é uma doença geralmente crônica e de grande polimorfismo, podendo se apresentar de diversas formas clínicas. As mais comuns são a linfocutânea e a cutânea fixa5 22.
As áreas do corpo expostas a traumas (membros superiores, face e membros inferiores) são as mais acometidas22. As formas disseminadas (cutânea disseminada e extracutânea) resultam de disseminação hematogênica do fungo a partir de um foco de inoculação inicial, com exceção da forma pulmonar que parece se dar através da inalação de conídios19 22. Estas formas podem estar relacionadas a algum grau de imunodeficiência e a doença pode ser considerada oportunista. Além disso, alcoolismo tem sido reconhecido como fator de risco para esporotricose disseminada13.

Esporotricose acometendo pacientes infectados pelo HIV tem sido relatado desde o início da epidemia2 11 . Há descrição de casos com manifestações clínicas variadas 41017 predominando as formas disseminadas, incluindo comprometimento articular, meníngeo e de seios da face 6781824 . No Brasil, não encontramos caso de esporotricose em AIDS descrito na 
literatura pesquisada pelos sistemas Medline e Lilacs. A região de Ribeirão Preto é sabidamente endêmica para outras infecções fúngicas, especialmente a paracoccidioidomicose e a histoplasmose existindo em nosso serviço uma casuística relevante de ocorrência dessas doenças em pacientes infectados pelo HIV14 15. Dados antigos sobre a prevalência de infecção por S. schenckii no estado de São Paulo apontavam a doença como sendo a segunda micose subcutânea mais comum após a paracoccidioidomicose 5. O Hospital das Clínicas da Faculdade de Medicina de Ribeirão Preto tem recebido nos últimos anos alguns casos de esporotricose em pacientes imunocompetentes. Entretanto, este é o primeiro caso de doença em paciente com infecção pelo HIV.

A pesquisa do agente etiológico no pus, escamas ou cortes histológicos da pele pode ser feita a fresco ou após coloração específica (Gram, PAS, Giemsa, Gomori) e habitualmente é negativa devido a escassez de elementos parasitários nas formas cutâneas 13 , sendo positiva com mais freqüência em casos de doença disseminada e doença associada a SIDA. Já o isolamento e identificação do S. schenckii a partir de cultura de amostras de áreas acometidas tem sido descrito como sendo extremamente fácil19 e é o método de escolha para confirmação diagnóstica. Isolamento a partir de hemocultura tem sido descrito como raro e apenas nas formas disseminadas da doença com ou sem lesão cutânea9. Testes sorológicos são indicadores altamente específicos 1922 , sendo os títulos positivos após três a quatro semanas. São particularmente úteis para diagnóstico de esporotricose extracutânea ou para monitorizar resposta ao tratamento1. Scott et al21 compararam isolamento em cultura e pesquisa de anticorpos em líquor e sangue como parâmetro para o diagnóstico e tratamento de meningite por S. schenckii em sete pacientes, observando boa

medicamento.

\section{REFERÊNCIAS BIBLIOGRÁFICAS}

1. Belknap BS. Sporotrichosis. Dermatologic Clinics 7:193202, 1989.

2. Bibler MR, Luber HJ, Gluck HI, Estes SA. Disseminated sporotrichosis in a patient with HIV infection after treatment for acquired factor VIII inhibitor. Journal of American Medical Association 256:3125-3126, 1986.

3. Coker RJ, Viviani M, Gazzard BG, Du Pont B, Pohle HD, Murphy SM, Atouguia J, Champalimaud JL. Treatment of correlação em todos os casos. O paciente aqui relatado teve confirmação diagnóstica através de isolamento do $S$. schenckii em cultura de tecido. Não se isolou o fungo a partir de hemocultura. Foram também constatadas estruturas fúngicas em exame histopatológico de lesão cutânea. Além disso, em amostra de soro estocada e testada posteriormente para pesquisa de anticorpos através de contra-imunoeletroforese, detectou-se presença dos mesmos em titulação de $1 / 32$.

Terapia clássica com iodetos pode ser eficaz para formas cutânea fixa e linfocutânea da esporotricose, mas os efeitos adversos associados, a necessidade de ajuste progressivo da dose e os resultados ruins associados com doença disseminada fazem dessa droga uma alternativa pouco útil em pacientes com infecção pelo HIV ou outras condições relacionadas a imunodeficiência1 22 23. Resultados com o uso de ketoconazol para tratamento de esporotricose em pacientes sem infecção pelo HIV têm sido desapontadores, apesar da suscetibilidade à droga in vitro18. Itraconazol se mostrou eficaz contra esporotricose cutânea fixa e linfocutânea, doença pulmonar, e fungemia mesmo após a terapia com anfotericina B ter falhado5 182223. As formas disseminadas da esporotricose têm sido manuseadas com sucesso em pacientes com infecção pelo HIV tratados com anfotericina B $(0,25 \text { a } 1 \mathrm{mg} / \mathrm{kg} / \mathrm{dia})^{2} 6$ ou itraconazol $(400 \mathrm{mg} / \mathrm{dia}) 1822$ 23. Forma lipossomal de anfotericina $B$ tem sido recentemente utilizada no tratamento de infecções fúngicas graves em pacientes imunodeficientes e que apresentam intolerância à anfotericina $\mathrm{B}$ convencional3 16 . Não há descrição na literatura do uso de anfotericina $B$ forma lipossomal para tratamento de esporotricose disseminada em portadores de infecção pelo HIV. Nosso paciente apresentou boa tolerabilidade e excelente resposta terapêutica com 0 uso deste

cryptococcosis with liposomal amphotericin B (AmBisome) in 23 patients with AIDS. AIDS 7:829-835, 1993.

4. Donabedian H, O’Donnell E, Olszewski C, MacCarthur RD, Budd N. Disseminated cutaneous and meningeal sporotrichosis in an AIDS patient. Diagnostic Microbiology Infectious Disease 18:111-115, 1994.

5. Donadel KW, Reinoso YD, de Oliveira JC, Azulay RD. Esporotricose: revisão. Anais Brasileiros de Dermatologia 68:45-52, 1993.

6. Fitzpatrick JE, Eubanks S. Acquired immunodeficiency 
syndrome presenting as disseminated cutaneous sporotrichosis. Internal Journal of Dermatology 27:406407, 1988.

7. Heller HM, Fuhrer J. Disseminated sporotrichosis in patients with AIDS: case report and review of the literature. AIDS 5:1243-1246, 1991.

8. Keiser P, Whittle D. Sporotrichosis in human immunodeficiency virus-infected patients: report of a case [letter]. Reviews of Infectious Diseases 13:10271208, 1991.

9. Kosinski RM, Axelrod P, Rex JH, Burday M, Sivaprasad $\mathrm{R}$, Wreiole A. Sporothrix schenckii fungemia without disseminated sporotrichosis. Journal of Clinical Microbiology 30:501-503, 1992.

10. Kurosawa A, Pollock SC, Collins MP, Kraff CR, Tso MOM. Sporothrix schenckii endophthalmitis in a patient with human immunodeficiency virus infection. Archives of Ophthalmology 106:376-380, 1988.

11. Lipstein-Kresch E, Isenberg HD, Singer C, Cooke O, Greenwald RA. Disseminated Sporothrix schenckii infection with arthritis in a patient with acquired immunodeficiency syndrome. Journal of Rheumatology 12:805-808, 1985.

12. Londero AT, Ramos CD. Esporotricose no Rio Grande do Sul: três décadas de observação. Anais Brasileiros de Dermatologia 64:307-310, 1989.

13. Lynch PJ, Voorhees JJ, Harrel ER. Systemic sporotrichosis. Annals of Internal Medicine 73:23-30, 1970.

14. Machado AA, Coelho ICB, Roselino AMF, Trad ES, Figuriredo JFC, Martinez R, Costa JC. Histoplasmosis in individuals with acquired immunodeficiency syndrome (AIDS): report of six cases with cutaneous-mucosal involvement. Mycopathologia 115:13-18, 1991.
15. Martinez R, Figueiredo JFC, Machado AA, Figueiredo LTM, Castro G, Moya MJ. Paracoccidioidomicose oportunista em pacientes com infecção pelo HIV 1 e SIDA. The Brazilian Journal of Infectious Diseases 1:S18-S18, 1997.

16. Mills W, Chopra R, Linch DC, Goldstone AH. Liposome Amphotericin $\mathrm{B}$ in the treatment of fungal infection in neutropaenic patients: a single centre experience of 133 episodes in 116 patients. British Journal of Haematology 8556:754-760, 1994.

17. Morgan M, Reves R. Invasive sinusitis due to Sporothrix schenckii in a patient with AIDS. Clinical Infectious Diseases 23:1319-1320, 1996.

18. Oscherwitz SL, Rinaldi MG. Disseminated sporotrichosis in a patient infected with human immunodeficiency virus. Clinical Infectious Diseases 15:568-569, 1992.

19. Pluss JL, Opal SM. Pulmonary sporotrichosis: review of treatment and outcome. Medicine (Baltimore) 65:143153,1986

20. Richardson MD, Warnock DW. Fungal infection: diagnosis and management. 1st edition, Blackwell, Oxford, p. 186189, 1993.

21. Scott EN, Kaufman L, Brown AC, Muchmore HG. Serologic studies in diagnosis and management of meningitis due to Sporothrix schenckii. The New England Journal of Medicine 317:935-940, 1987.

22. Severo LC, Londero AT. Micoses Subcutâneas. In: Veronesi R, Focaccia R (eds) Tratado de Infectologia, 9a edição, Livraria Atheneu, São Paulo. p. 1044-1045, 1997.

23. Sharkey-Mathis PK, Kauffman CA, Graybill JR, Stevens DA, Hostetler JS, Cloud G, Dismukes WE. Treatment of sporotrichosis with itraconazole. The American Journal of Medicine 95:279-285, 1993. 